\title{
Entre teoria e prática: o que dizem os alunos do 90 ano do ensino fundamental de uma escola pública?
}

\author{
Ana Julia Becker ${ }^{1}$ \\ Angelica Vier Munhoz ${ }^{2}$ \\ Claudia Inês Horn ${ }^{3}$
}

\begin{abstract}
Resumo
Esta investigação foi realizada por uma bolsista CNPq Ensino Médio, vinculada ao Grupo de Pesquisa Currículo, Espaço, Movimento (CEM/CNPq/Univates), com o objetivo de analisar o modo como espaços escolares e não escolares produzem práticas educativas e artísticas em meio aos processos de ensinar e aprender. Nesta investigação, buscou-se aproximação com uma das escolas, a fim de compreender como os estudantes do $9^{\circ}$ ano do Ensino Fundamental percebem os processos de ensinar e aprender. A genealogia, de Michel Foucault (2005), foi o aporte metodológico da investigação, assim como serviu de aporte teórico para o estudo. A recorrência da dicotomia teoria e prática, na fala dos alunos, mostrou que ainda há uma dissociabilidade dessas questões no contexto da escola.
\end{abstract}

Palavras-chave: Escola; Teoria; Prática.

\section{Between theory and practice: what do ninth-grade students from an elementary public school say?}

\section{Abstract}

A High School CNPq student taking part in the Curriculum, Space, Movement Research Group (CNPq/Univates) carried out this investigation. The aim was to analyze the way that both school and non-school settings have produced educational and artistic practices along with teaching and learning processes. In this study, we have attempted to approach one of the empirical fields - a public school in Vale do Taquari - in order to understand how $9^{\text {th }}$-grade students have regarded teaching and learning processes. The recurrence of issues concerning theory and practice in the students' statements has provided the investigation with a new path, thus encouraging the problematization of such an indissociability, which is still present in the school context.

Keywords: School; Theory; Practice.

\section{Introdução}

O presente artigo resulta de uma investigação realizada por uma bolsista CNPq Ensino Médio, vinculada ao Grupo de Pesquisa Currículo, Espaço, Movimento (CEM/CNPq), da Universidade do Vale do Taquari, no período de 2017 a 2019. O referido Grupo de Pesquisa, existente desde 2013, tem por objetivo compreender e problematizar o modo como os espaços

\footnotetext{
${ }^{1}$ Universidade do vale do Taquari - Univates, Lajeado/RS, ana.becker2@universo.univates.br

2 Universidade do vale do Taquari - Univates, Lajeado/RS, angelicavmunhoz@gmail.com

${ }^{3}$ Universidade do vale do Taquari - Univates, Lajeado/RS, cihorn@univates.br
} 
escolares e não escolares vêm produzindo práticas educativas e artísticas em meio aos processos de ensinar e aprender, tomando espaços escolares (duas escolas públicas) e espaços não escolares (quatro espaços de arte) como espaços de investigação. O pensamento da Filosofia da Diferença, a partir dos autores Deleuze \& Guattari e Foucault é tomado como aporte teórico do Grupo de pesquisa. Por outra via, as discussões curriculares também se tornam centrais para a construção do plano conceitual da pesquisa, sobretudo as teorizações curriculares pósestruturalistas, propostas por pensadores brasileiros, como Sandra Corazza, Tomaz Tadeu, Alfredo Veiga-Neto, entre outros. As aproximações genealógicas com Foucault delinearam o método de pesquisa do Grupo CEM, mas também a genealogia se tornou um conceito importante a ser percorrido nos estudos do grupo.

Em meio aos objetivos do Grupo CEM, nesta investigação, pretendeu-se uma aproximação de um dos campos empíricos - uma escola pública da região do Vale do Taquari a fim de compreender como os estudantes do $9^{\circ}$ ano do Ensino Fundamental percebem os processos de ensinar e aprender. A investigação foi realizada em dois momentos, que coincidiram com os dois anos de Bolsa CNPq-EM, nos quais foram desenvolvidos os seguintes projetos: a) Aprender e ensinar na escola atual; b) Aprender e ensinar na perspectiva dos estudantes do 9o ano do Ensino Fundamental.

No primeiro projeto, desenvolvido no período de agosto de 2017 a julho de 2018, buscouse, inicialmente, uma aproximação da escola, a fim de conhecer seu funcionamento, dinâmica e práticas realizadas. A primeira aproximação ocorreu em uma visita, na qual três representantes da turma do $9^{\circ}$ ano acompanharam a bolsista, mostrando alguns lugares que consideravam importantes na escola. O outro encontro foi realizado com todos os alunos do 9 o ano, com o propósito de entender, por meio de entrevistas, como eles percebiam os processos de ensinar e aprender. Nesse encontro, foi possível evidenciar que a questão da teoria e prática era bastante recorrente nas falas dos alunos. Assim, no segundo projeto, desenvolvido no período de agosto de 2018 a julho de 2019, retornou-se à escola, abordando-se a nova turma de alunos do $9^{\circ}$ ano, para investigar mais detalhadamente como tais alunos compreendiam as relações entre teoria e prática.

Uma aproximação com a perspectiva genealógica, com base em Michel Foucault (2005), também foi o aporte metodológico que deu sustentação à investigação aqui relatada. Para 
Foucault, a genealogia constitui-se em um modo "[...] de fazer da história um uso que a liberte para sempre do modelo, simultaneamente metafísico e antropológico, da memória. Trata-se de fazer da história uma contramemória e de desdobrar, consequentemente, uma forma totalmente diferente do tempo" (FOUCAULT, 2005, p.277). Para isso, há de se descrever os acontecimentos discursivos, os seus encadeamentos, os lugares institucionais nos/dos quais essas práticas são produzidas. Em meio a perspectiva genealógica, diferentes estratégias metodológicas, foram utilizadas na investigação: a) observações na escola; b) encontros e conversas com alunos; c) registros escritos e anotações em diário de campo; d) entrevistas com alunos participantes; e) transcrições das entrevistas; f) análise do material produzido.

Todos esses procedimentos realizados, assim como os materiais produzidos e analisados serão apresentados em forma de relatos, no entremeio da descrição do processo investigativo, na seção que segue. Cabe destacar que todos os participantes assinaram o termo de consentimento livre e esclarecido, autorizando o uso de suas falas, colhidas durante a investigação.

Iniciamos assim o texto, com um breve relato dessas inserções na escola, destacando os encontros com os alunos, o percurso da investigação e as questões que foram orientando as conversas com alunos, assim como, os seus retornos. Como as questões da teoria e da prática ganharam visibilidade na voz dos alunos, busca-se compreender, na seção seguinte, de que modo as relações, ou melhor, as dissociações entre teoria e prática foram se constituindo no contexto da educação. Por fim, intenciona-se teorizar sobre tais questões, procurando mostrar a indissociabilidade entre teoria e prática e, ao mesmo tempo, apresentar as discussões feitas no grupo CEM, mapeando algumas considerações finais para seguir problematizando nosso próprio pensamento.

\section{O que pensam e dizem os alunos do 99 ano do Ensino Fundamental?}

Como aluna de Ensino Médio, entrar na escola (em qualquer escola) fazia parte da rotina diária da bolsista pesquisadora. Essa não era a sua escola, mas isso não fazia diferença. Para os estudantes, ela também poderia ser somente mais uma aluna habitando aquele espaço. Contudo, transitar por aquele local, não sendo uma aluna da escola, mas uma bolsista de Ensino 
Médio de um Grupo de Pesquisa, era algo completamente novo para ela. Então, enquanto aguardava os alunos, ela observava todos os lugares, se deparava com lembranças principalmente do Ensino Fundamental -, analisava os trabalhos desenvolvidos pelas turmas, observava os alunos que circulavam e o andar do cotidiano da escola.

Durante essa espera, sentia-se um pouco nervosa; estava sozinha, e, como era seu primeiro contato com a escola, parecia difícil. No momento em que os alunos chegaram, ela se apresentou. Os três alunos apresentaram-se também, envergonhados, porém curiosos, e queriam logo Ihe mostrar a escola. Começaram pelo pátio; depois, mostraram-lhe a quadra coberta, a biblioteca, a sala de informática, a horta, as salas de aula e, por último, a sua própria sala de aula. Ela observou que suas classes estavam todas coloridas. Curiosa, perguntou-Ihes o motivo, e contaram-Ihe que nas séries finais os alunos podem decorar suas próprias classes; o intuito era incentivá-los a irem à escola. Por fim, foram até o miniauditório, onde a bolsista explicou um pouco de seu projeto de investigação, fez algumas perguntas e obteve respostas interessantes. De imediato, recebeu um feedback dos alunos e uma primeira recepção do projeto, pois os três alunos presentes se mostraram muito interessados e lhe passaram uma sensação de segurança.

Quando ela saiu da escola, fez algumas anotações e teve algumas ideias. Após este encontro, junto com a orientadora, marcaram um novo encontro, agora com toda a turma de estudantes. O objetivo era, então, compreender o que os alunos pensavam sobre o aprender e o ensinar. Nesse dia, levaram à escola três imagens selecionadas de um projeto de uma das professoras do grupo de pesquisa. Tais imagens eram impressões de fotografias feitas por alunos de escolas públicas e particulares de Ensino Fundamental da região e apresentavam, grosso modo, as suas impressões sobre as funções da escola na contemporaneidade. A bolsista e a orientadora achavam que tais fotografias pudessem impulsionar o debate inicial. Também levaram post-its, diário de bordo para anotações e um gravador de áudio para registrar as entrevistas. Além disso, levaram os termos de consentimento livre e esclarecido, os quais foram assinados pelos participantes, autorizando o uso de imagens, áudios e vídeos. Nessa manhã, elas indagaram os alunos sobre duas questões: "Como vocês aprendem?" e "Como vocês percebem os espaços de ensinar e aprender na escola?". Observar os alunos interpretando as questões e respondendo-as utilizando um post-it foi muito gratificante, pois perceberam que os estudantes 
estavam muito envolvidos na atividade. Por outro lado, fazê-los pensar sobre a escola em que estavam inseridos era instigante, pois a bolsista de Ensino Médio via suas respostas em seus próprios colegas e conseguia aproximar de seu cotidiano as questões levantadas.

Após esse encontro, a bolsista realizou a transcrição das respostas advindas do áudio, explorou as respostas retiradas dos post-its e avaliou os procedimentos junto com a orientadora. Após aprender a organizar e a analisar dados, novamente com a orientadora, discutiu a análise e percebeu que algumas das questões não estavam muito claras, pois os alunos deram respostas como estas selecionadas no quadro abaixo:

Quadro 1: Depoimentos dos alunos sobre o ensinar e o aprender

ALUNO 3: "Ter aula mais ao ar livre".

ALUNO 16: "Fazer atividades mais dinâmicas, não só copiando".

ALUNO 19: “Tudo evoluiu, o mundo evoluiu, mas o jeito de a gente aprender não evoluiu, tipo, está sempre o mesmo".

ALUNO 16: “No último dia, a gente tem vontade de vir para a escola, porque não é só copia, copia, copia..."

ALUNO 20: "Tu participas bem mais tendo aula prática do que uma aula teórica". ALUNO 16: “É que, tipo, a gente fazendo uma aula prática é algo diferente, aí, a gente vai guardar, tipo, só copiando, a gente não vai lembrar".

Fonte: Diário de Campo da Bolsista Pesquisadora/2018

Tais questões estavam centradas na fragmentação entre teoria e prática, ou seja, a bolsista e sua orientadora inquietaram-se com a recorrência de falas sobre a preferência por aulas práticas e um possível "desgosto" em relação às aulas teóricas. Ora, o que esses alunos estão pensando em relação à aula prática e à aula teórica? Há diferença? Há separação? Decidiram, então, retornar à escola para compreender melhor essas questões que envolviam a teoria e a prática - tão reincidentes nas falas dos alunos. Para isso, foi necessário retornar ao projeto e formular novas indagações, as quais dariam norte também ao presente artigo. Tentaram marcar um novo encontro com a escola ainda antes de o ano letivo acabar, mas, infelizmente, não conseguiram, pois o ano estava em fase final. 
Desse modo, tanto o objetivo geral da investigação, quanto os objetivos específicos foram readequados à demanda surgida. Se o objetivo inicial era compreender como os estudantes do $9^{\circ}$ ano do Ensino Fundamental percebem os processos de ensinar e aprender, agora se tratava de compreender como os estudantes do $9^{\circ}$ ano do Ensino Fundamental percebiam as questões de teoria e prática, em suas aulas. Assim, os objetivos específicos também foram redefinidos, seguindo os rumos da pesquisa empírica e agregando a nova problemática colocada pelos estudantes envolvidos. Tais objetivos se reconfiguraram em: a) realizar entrevistas com alunos dos $9^{\circ}$ ano do Ensino Fundamental; b) analisar as respostas e agrupá-las em categorias.

Durante as férias escolares, a bolsista pesquisadora foi aperfeiçoando suas ideias e desenvolvendo as questões que no ano seguinte seriam feitas aos novos alunos do $9^{\circ}$ ano. Nesse novo encontro, ela deveria concentrar-se em questões específicas, tais como: "O que vocês compreendem por prática?", "O que vocês compreendem por teoria?", "O que vocês compreendem por aulas teóricas?", "O que vocês compreendem por aulas práticas?" e "Como vocês gostariam que fossem as aulas?".

Com o reinício do ano letivo, foi marcado um encontro com os alunos, e dessa vez a bolsista iria sozinha. O encontro foi marcado para uma tarde, fora do horário de aula. Compareceram cinco alunos; quando a bolsista chegou à escola, eles já estavam aguardando. A diretora levou-os até a biblioteca, onde ficaram, e iniciou-se a conversa. Para essa entrevista, também foram utilizados gravador de áudio e um diário de bordo. Destacam-se, agora, alguns fragmentos das falas dos alunos, em resposta às questões acima citadas, organizando-se dois quadros - um que aborda os depoimentos dos alunos em relação às noções de teoria e outro sobre prática.

Quadro 2: Depoimentos dos alunos sobre concepções de teoria/aula teórica

ALUNO 1: "Teoria é passar exercícios no livro...".

ALUNO 2: "Teoria é aquilo que é passado sem diálogo...".

ALUNO 3: "Teoria é copiar coisa do quadro...".

ALUNO 4: "Aquilo que sempre tem uma única forma de ser feito...".

ALUNO 5: "Teoria é aquilo sem expressão de ideia".

Fonte: Diário de Campo da Bolsista Pesquisadora/2019 
Quadro 3: Depoimentos dos alunos sobre concepções de prática/aula prática

ALUNO 1: "Numa aula prática, a gente pode se expressar...".

ALUNO 2: "Prática é ler um livro e depois colocar em prática aquilo que se aprendeu através da leitura". ALUNO 3: "Fazer experimentos em laboratório".

ALUNO 4: “Debates são aulas práticas, pois mostramos nossos pontos de vista".

ALUNO 5: "Teatro, por exemplo, é uma aula prática".

ALUNO 1: "Eu gostaria de mais passeios como atividade escolar".

ALUNO 2: "Gostaria de aprender coisas para a vida".

ALUNO 3: "Não ficar só na sala de aula".

ALUNO 4: "Que as aulas fossem mais mistas".

ALUNO 5: "Aprender culinária e novas coisas".

Fonte: Diário de Campo da Bolsista Pesquisadora/2019

A partir dessas respostas, pode-se perceber que os alunos estavam insatisfeitos com algumas formas de ensino, pois deixam claras as suas críticas e indignação quanto ao modo como se dão as aulas. Dessa forma, a pesquisa empírica mostra o quanto são recorrentes, na voz dos alunos, a separação entre teoria e prática e, como possível consequência desse binarismo, uma preferência por cada vez mais aulas práticas.

\section{Teoria e prática: um percurso histórico de dissociabilidade}

A relação entre teoria e prática já há muito tem sido discutida no campo da educação. Contudo, o que vemos é uma dicotomia entre essas duas instâncias. Herança do pensamento platônico, que no século XVII encontra força em Descartes, o binômio teoria e prática ainda sustenta o modo de compreender o mundo no ocidente.

Grande parte da tradição filosófica é orientada pelo pressuposto de que, entre o pensamento e a verdade, haveria uma natural afinidade, de forma que o esforço do pensamento é sempre encontrar tal verdade, a qual está no mundo da racionalidade, no mundo das ideias. Esse mundo das ideias é, para Platão, superior ao mundo das coisas. Compreende-se, assim, que na Antiguidade Grega havia uma hierarquia de valores que considerava o trabalho manual, a prática do artesão, como inferior à atividade intelectual do pensador. Ao intelectual, homem 
livre, pertencia o mundo das ideias.

Tal dualismo platônico reconfigura-se com Descartes e incide ainda mais na valorização da teoria em relação à prática, do racional sobre o corporal, do trabalho intelectual sobre o trabalho manual. A teoria, nessa perspectiva cartesiana, é compreendida como a única forma de saber legítimo, em detrimento de saberes da experiência, dos saberes do corpo. O primado da teoria sobre a prática é o que sustenta o paradigma científico positivista, partindo-se da teoria para a prática, ou seja, da abstração teórica para a comprovação do conhecimento por meio da prática.

[...] o dualismo platônico foi contrabandeado para a Ciência moderna, manifesto pela noção de que as teorias estão no mundo das ideias - devendo ser, portanto, perfeitas, rigorosas, abrangentes e definitivas -, enquanto que as práticas estão neste nosso mundo sensível, são coisas deste mundo concreto e imperfeito. Assim, segundo esse entendimento, quando os resultados obtidos na prática não se ajustam perfeitamente à teoria - e nunca acontece de fato um ajuste perfeito -, pensa-se logo que ou o problema está na teoria que seria incorreta ou pouco desenvolvida, ou o problema está no mau ou equivocado uso que estamos fazendo dela. Em qualquer caso, mantém-se tacitamente que existe mesmo um mundo da prática e um mundo das ideias, cabendo à boa Ciência fazer as melhores conexões entre esses dois mundos (VEIGA-NETO, 2015, p.12).

Essa divisão também acarretou a divisão social do trabalho. 0 trabalho intelectual se sobrepôs ao trabalho manual, engendrando "uma postura de domínio de apropriação dos que detém o poder das ideias em relação aos práticos. Sem dúvida, isso reflete também a divisão social do trabalho numa sociedade de classes, onde há uma separação entre trabalho manual e trabalho intelectual" (FÁVERO, 1981, p.15).

Tal relação hierárquica incidiu na educação do final do século XIX, constituindo duas modalidades de ensino: uma voltada para a classe proprietária, identificada como a educação dos homens livres, e outra destinada aos escravos, serviçais e todos os que não tinham condições sociais satisfatórias. A primeira diz respeito às atividades intelectuais, à arte da palavra, além dos exercícios físicos de caráter lúdico ou militar. Assim, para os filhos das elites, assegurava-se uma escola das ciências, das letras e das artes, e a educação cumpria a sua função de contribuir para a reprodução das classes sociais. A segunda, com caráter assistencialista, era destinada aos trabalhos manuais. "Crianças e jovens em estado de mendicância eram encaminhados para essas 
casas, onde recebiam instrução primária [...] e aprendiam alguns dos seguintes ofícios: tipografia, encadernação, alfaiataria, tornearia, carpintaria, sapataria etc." (MANFREDI, 2002, p.76-77).

A educação básica brasileira é estruturada no início do século XX de uma forma binária, com a diferenciação de percursos educativos dos filhos das elites e dos filhos da classe trabalhadora, desde o curso primário. Havia um curso primário com duração de quatro anos para aqueles cujo percurso tinha como fim a educação superior e curso rural ou profissional destinado às crianças das classes populares (KUENZER, 1997).

Com efeito, é possível evidenciar, ainda que brevemente, a valorização de uma educação de cunho mais teórico, em detrimento daquela voltada para a força de produção econômica separação que reforça a divisão de classe social. Contudo, na segunda metade do século XX, começamos a perceber uma curvatura da vara, ou seja, com a tentativa de romper a dicotomia teoria e prática, passa-se a supervalorizar o corpo, as coisas, as ações, as atividades práticas. Esse movimento ganha consistência na educação nas décadas de 60 e 70, com o início das discussões sobre um ensino por competências. Para Ropé e Tanguy (1997), desde o início, a noção de competências estaria associada a uma qualificação voltada a um saber-fazer, atribuindo-se um sentido prático aos saberes escolares, abrindo-se às demandas do mercado de trabalho: "[...] a escola progressivamente aproximou-se do mundo das empresas por meio de cooperações de todos os tipos, e também por revisões na maneira de pensar os conteúdos de ensino, organizar os modos de transmissão dos saberes e de avaliá-los" (ROPÉ; TANGUY, 1997, p.18).

Nessa perspectiva, aprender virou um dispositivo mercadológico, tornando-se algo absolutamente utilitário, ou seja, aprende-se para alcançar uma competência ou para cumprir uma tarefa. Por outra via, ensinar diz respeito, hoje, a ensinar competências ou habilidades úteis para o mercado de trabalho. Tal como afirma Larrosa (2018, p.244), "se a força de trabalho era o que movia as máquinas da fábrica industrial, agora é a força da aprendizagem o que move os aparatos da força cognitiva". Por tal razão, aprender e ensinar exigem, gradativamente, menos trabalho de pensamento e mais trabalho de produção. Por outro lado, a lógica das competências também leva para a privatização do indivíduo, de modo que a educação passa a ser um caminho para a empregabilidade individual, mais do que qualquer projeto de sociedade.

O que interessa aqui não é qualificar a primazia da teoria sobre a prática ou vice-versa, mas dar a ver que, ora privilégio de um, ora de outro, continuamos a pensar binariamente, por 
separação e oposição. O desafio que se coloca, portanto, é como pensar a teoria e a prática não como dicotômicas, mas como interfaces de um mesmo plano na educação. É sobre essa questão que estruturamos a seção seguinte.

\section{Relações entre teoria e prática em meio à aula}

Optamos por compreender as relações entre teoria e prática sob uma perspectiva pósestruturalista, a qual fundamenta as discussões desenvolvidas no Grupo de Pesquisa CEM/Univates, também abordadas neste artigo. Por esse motivo, escolhemos fazer referência ao filósofo francês Michel Foucault, quando afirma que a teoria deve ser, antes de tudo, uma prática: “É por isso que a teoria não expressará, não traduzirá, não aplicará uma prática; ela é uma prática" (FOUCAULT, 2001, p.71).

Podemos fazer menção a três autores estudiosos de Foucault: Santiago Castro-Gómez, Edgardo Castro e Alfredo Veiga-Neto, que dialogam sobre as relações entre teoria e prática; dito de outro modo, esses autores mostram que a teoria é uma prática e que em toda prática há sempre uma teorização.

Para Castro-Gómez (2010), prática é “aquilo que realmente os homens fazem quando falam ou quando agem. Ou seja, as práticas não são expressão de algo que esteja 'atrás' do que se faz (o pensamento, o inconsciente, a ideologia ou a mentalidade), senão que são sempre manifestas" (CASTRO-GÓMEZ, 2010, p.28). Castro (2009) corrobora tal noção ao afirmar que:

\footnotetext{
Foucault entende por práticas a racionalidade ou a regularidade que organiza o que os homens fazem (Sistema de ação na medida em que estão habitados pelo pensamento), que têm um caráter sistemático (saber, poder, ética) e geral (recorrente) e, por isso, constituem uma experiência ou um pensamento (2009, p.338).
}

Assim, as práticas definem-se pela regularidade e pela racionalidade dos modos de fazer (CASTRO, 2009). Veiga-Neto (2015) diz que podemos pensar a prática como o domínio daquilo a ser descrito, analisado e problematizado e, ao mesmo tempo, como o domínio das próprias descrições, análises e problematizações colocadas em movimento.

Tais afirmações ajudam-nos a compreender que, junto de qualquer prática, existe sempre 
uma teorização, mesmo que ela não esteja visível. Dito de outro modo, uma prática sempre implica uma questão epistemológica, ou seja, um modo de pensar e compreender o mundo. Não há pensamento ou teorização que não tenha nascido de alguma experiência, a qual é sempre da ordem do vivível ou, se preferirmos assim chamar, da ordem de uma prática.

Distanciando-se de uma perspectiva cartesiana que separa os tempos e os espaços entre o que diz respeito à teoria e o que diz respeito à prática, optamos por pensar a indissociabilidade entre elas. Contudo, retomando a problemática central deste artigo e as falas dos estudantes do 9o ano do Ensino Fundamental de uma escola pública, podemos interrogar: de que modo uma aula está fragmentada em dois tempos e espaços - uma aula teórica e uma aula prática? E mais: por que há preferências, por parte dos jovens, por aulas práticas? Por que acreditam aprender mais em aulas práticas?

Procurando hipóteses para responder tais questões, iniciemos por problematizar a aula. Larrosa (2018, p.71) afirma que uma aula "significa duas coisas: um espaço e um tempo"; um espaço de sala de aula que precisa ser cuidadosamente pensado, uma vez que é o lugar essencial do fazer do professor, diz o autor. Ele enfatiza: "é ao entrar na sala de aula que o aluno se converte em aluno e que o professor se converte em professor" (LARROSA, 2018, p.72). Espaços e tempos de uma aula que é da ordem da prática, não considerando aqui as regularidades da ordem do discurso inovador, por exemplo, das metodologias ativas, do ensino por meio de competências e habilidades, ou outro blá blá blá que se instale. Em outras palavras, importa o que acontece entre estudantes e professores; os encontros entre sujeitos e conhecimento. Uma aula aciona, põe na mesa, torna pública a matéria de estudo - o conhecimento -, que é responsabilidade do professor para com os seus estudantes. Nesse sentido, argumentamos que não importa tanto "onde" essa aula acontece, nem "que metodologias" ela abarca; importa o que acontece entre.

Sem pretender separar, defender ou privilegiar uma aula teórica ou uma aula prática, temos a intenção de problematizar nossas próprias representações acerca do que entendemos por teoria e prática, analisando as condições de emergência que tornaram tal divisão tão potente, ainda nos tempos atuais. Pensar que "teoria é aquilo sem expressão de ideia" e que "prática, a gente pode se expressar" pode fragilizar a epistemologia de uma aula. 


\section{Considerações finais}

A investigação inicial tinha por propósito a aproximação com uma escola pública - campo empírico do Grupo de Pesquisa Currículo, Espaço, Movimento (CEM/CNPq/Univates) - com vistas a compreender como os estudantes do $9^{\circ}$ ano do Ensino Fundamental percebem os processos de ensinar e aprender. Contudo, a recorrência das questões da teoria e da prática nas falas dos alunos deu um novo rumo à investigação, levando-nos a problematizar tal indissociabilidade, ainda tão presente no contexto da escola.

Nas falas dos alunos investigados, percebia-se que essa dicotomia teoria e prática, de algum modo estava posta, o que decorria em uma preferência por aulas práticas, já que estas eram percebidas como mais dinâmicas, interativas, provocando mais a participação dos alunos. Certamente, essas impressões dos alunos estão pautadas em experiências de aulas que se constituem de modo fragmentado, disciplinarizado, com demarcações do que seria algo do campo teórico e o que seria do campo da prática. Geralmente essas dissociações são feitas colocando aquilo que é da ordem do pensamento como teoria e da ordem do corpo como prática, ou dito de outro modo, do pensar e do fazer, respectivamente. Contudo, o que se defende aqui é que essa binarização é irreal, considerando que a teoria é uma ferramenta que só faz sentido quando "é usada e gera circuitos imediatos com as várias práticas, que por sua vez operam alterações nas ferramentas ou mesmo implicam na construção de novas ferramentas teóricas" (Gallo, 2010, p.58). Desse modo, exercitar o pensamento já é uma ação prática que modifica o que está sendo teorizado, na medida em que interfere também na própria ação.

Se, como nos diz Michel Foucault (2001), a teoria é, antes de tudo, uma prática, a binarização da teoria e da prática torna-se um discurso esvaziado de sentido, constituindo-se, inclusive, como um "falso problema", na perspectiva de Veiga-Neto (2015). Nessa ótica, não se trata de encontrar uma solução para tal binarização, nem mesmo de partir em defesa da primazia de uma ou outra - a teoria antes da prática; a prática antes da teoria -, mas de mudar o modo de olhar para essa questão, assim como perceber que uma não existe sem a outra, ou melhor, teoria e prática fazem parte de um só e mesmo mundo.

Sem a pretensão de fechar as questões aqui analisadas, esperamos oferecer pistas para seguir pensando e problematizando o modo naturalizado de conceber teoria e prática na escola, 
especialmente em relação aos modos pelos quais os estudantes percebem os processos de ensinar e aprender na instituição escolar contemporânea. Configura-se a intenção desta pesquisa e, consequentemente, deste artigo, mostrar possibilidades de leitura do real, produzir linhas de forças, pontos de resistências, dar vida à cultura do estranhamento sobre aquilo que falamos e fizemos na escola e, sobretudo, instaurar a dúvida, suspender certezas, resistir aos clichês e as representações sobre as quais repousamos o nosso pensamento no campo educacional.

\section{Referências}

CASTRO, E. Vocabulário de Foucault: um percurso pelos seus temas, conceitos e autores. Belo Horizonte: Autêntica, 2009.

CASTRO-GÓMEZ, S. Historia de la gubernamentalidad: razón de Estado, liberalismo y neoliberalismo en Michel Foucault. Bogotá: Siglo del Hombre Editores; Pontificia Universidad Javeriana - Instituto Pensar; Universidad Santo Tomás de Aquino, 2010.

FÁVERO, M. L. Sobre a formação do educador. A formação do educador: desafios e perspectivas. Rio de Janeiro: PUC/RJ, 1981.

FOUCAULT, M. Microfísica do poder. Trad. Roberto Machado. 16.ed. Rio de Janeiro: Graal, 2001.

FOUCAULT, M. Nietzsche, a genealogia e a história. In: MOTTA, M. B. (org.) Ditos e escritos, vol. II. Rio de Janeiro: Forense Universitária, 2005. p.260 -281.

GALLO, S. Filosofia da diferença e educação: o revezamento entre teoria e prática. In: CLARETO, S. M.; FERRARI, A. Foucault, Deleuze e Educação. Juiz de Fora: Ed. UFJF, 2010, p.45-63.

LARROSA, J. Esperando não se sabe o quê: sobre o ofício do professor. Trad. Cristina Antunes. Belo Horizonte: Autêntica, 2018.

KUENZER, A. Z. Ensino médio e profissional: as políticas do estado neoliberal. São Paulo: Cortez, 1997.

MANFREDI, S.M. Educação profissional no Brasil. São Paulo: Cortez Editora, 2002.

ROPÉ, F.; TANGUY, L. (orgs). Saberes e competências: o uso de tais noções na escola e na empresa. Campinas: Papirus, 1997. P.15-67. 
TANGUY, L. Competências e integração social na empresa. In: ROPÉ, F.; TANGUY, L. (orgs).

Saberes e competências, o uso de tais noções na escola e na empresa. São Paulo: Papirus, 1997. p. 15-67.

VEIGA-NETO, A. Anotações sobre as relações entre teoria e prática. In: PINTO, T. J. S.; CUNHA, M. V.(org.). Educação em Foco, Juiz de Fora v.20, n.1, p.113-140, mar./jun. 2015.

Recebido em agosto 2019.

Aprovado em junho 2020. 